\title{
ISOLATION OF VIRUS FROM EMBRYONATE EGGS INOCULATED WITH MATERIAL FROM A CASE OF TRACHOMA IN WESTERN AUSTRALIA*
}

BY

\author{
DOROTHY PERRET AND IDA MANN \\ Public Health Department, Perth, Western Australia
}

THE first convincing isolation of the trachoma virus was made by T'ang, Chang, Huang, and Wang (1957) using embryonate eggs: their findings were confirmed by Collier and Sowa (1958), who also showed that clinical trachoma followed inoculation of a human volunteer with isolated virus. Isolation of the virus from patients with trachoma in Australia has not previously been reported although the disease is common amongst the aborigines.

This communication describes an apparently successful isolation from a 3 -year-old half-caste boy living in the native camp at Moora, 100 miles north of Perth, Western Australia.

\section{Method}

The tarsal plates of both his eyes were scraped with a platinum spatula.

Direct Smear.-A smear made from the scraping from one eye was examined for inclusion bodies, using the staining method described by Collier, Duke-Elder, and Jones (1958). Typical inclusion bodies were present, staining reddish-brown with iodine and having the usual appearance with Giemsa-May-Grünwald stain.

Chick Embryo Inoculation.-The scraping from the other eye was put into $1 \mathrm{ml}$. 10 per cent. broth in saline containing 20,000 units streptomycin. 6 hours later, after transportation on ice, this fluid was inoculated by the yolk-sac route into three 7-day-old chick embryos. Incubation of the eggs was continued at $35^{\circ} \mathrm{C}$.

One embryo died 5 days later, but passage of its yolk sac failed to initiate obvious infection in further 7-day-old chick embryos; the second embryo died 11 days after inoculation and had petechial haemorrhages; and the third embryo was alive and apparently normal when harvested 13 days after inoculation. The yolk sacs from the second and third embryos were passaged separately, by the yolk sac route, seven and six times respectively (Table I): at each passage $0.2 \mathrm{ml}$. of a 20 per cent. suspension of yolk sac in 10 per cent. broth-saline containing 20,000 units streptomycin per ml. was inoculated into four or six 6- or 7-day-old chick embryos. At each passage most of the embryos were killed and death occurred most frequently 7-10 days after inoculation (Table I, overleaf).

* Received for publication October 14, 1959. 
TABLE I

RESULTS OF EGG PASSAGE

\begin{tabular}{|c|c|c|c|c|c|c|c|c|c|c|c|c|c|c|c|c|}
\hline \multirow{4}{*}{$\begin{array}{c}\text { Survival } \\
\text { Time of } \\
\text { Embryos } \\
\text { (days from } \\
\text { day of } \\
\text { inoculation) }\end{array}$} & \multicolumn{16}{|c|}{$\begin{array}{c}\text { Number of Embryos Dying or Surviving after Yolk-sac Inoculation } \\
\text { with Passaged Material from Patient T425 }\end{array}$} \\
\hline & \multicolumn{10}{|c|}{ Passages from Second Embryo } & \multicolumn{5}{|c|}{ Passages from Third Embryo } & \multirow{3}{*}{$\begin{array}{c}\text { Total Deaths } \\
\text { on Corre- } \\
\text { sponding } \\
\text { Days }\end{array}$} \\
\hline & \multirow{2}{*}{ Second } & \multicolumn{2}{|c|}{ Third } & \multirow{2}{*}{ Fourth } & \multicolumn{2}{|c|}{ Fifth } & \multicolumn{2}{|c|}{ Sixth } & \multicolumn{2}{|c|}{ Seventh } & \multirow{2}{*}{ Second } & \multirow{2}{*}{ Third } & \multirow{2}{*}{ Fourth } & \multirow{2}{*}{ Fifth } & \multirow{2}{*}{ Sixth } & \\
\hline & & a & b & & $\mathbf{a}$ & b & $\mathbf{a}$ & b & a & $\mathbf{b}$ & & & & & & \\
\hline$<4$ & & & 1 & 1 & & & & 1 & & & & & & 1 & & 4 \\
\hline 5 & & & & 1 & 2 & & & & & & & & & & & 3 \\
\hline 6 & & & & 2 & & & & & 2 & & & & & & 1 & 5 \\
\hline 7 & 1 & & 3 & 1 & & 2 & 1 & 3 & 1 & & 1 & 3 & 4 & & & 20 \\
\hline 8 & 2 & & & 1 & 1 & 2 & 1 & & 2 & & & & & & 1 & 10 \\
\hline 9 & 2 & 2 & & & 1 & & 2 & & & 1 & 3 & & 2 & & 1 & 14 \\
\hline 10 & 1 & 1 & & & 1 & & 2 & & 1 & 3 & 1 & 2 & 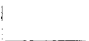 & 2 & & 14 \\
\hline 11 or 12 & & & 1 & 2 & & & & & & & 1 & & & & & 4 \\
\hline Survivors & 0 & 1 & 1 & 0 & 1 & 0 & 0 & 0 & 0 & 0 & 0 & 1 & 0 & 1 & 1 & 6 \\
\hline
\end{tabular}

Nearly all the dead embryos had the petechial haemorrhages described by Collier and Sowa (1958); their yolk sacs were more fragile than those of normal embryos of the same age, and the yolk was more fluid. Portions of yolk sac were repeatedly tested in serum broth, and cooked meat medium, and on horse blood agar, and occasionally on a medium suitable for pleuropneumonia-like organisms; bacterial growth was never observed, nor were bacteria seen in smears of the yolk sacs.

Examination of Yolk-Sac Smears.-Smears of yolk sacs were stained with Giemsa or Giemsa-May-Grünwald, stains or by Macchiovello's method. The smears from dead embryos showed bodies resembling the elementary bodies and the intracellular forms of the psittacosis-lymphogranuloma venereum ( $\mathrm{P}-\mathrm{LGV}$ ) group of viruses, and agreeing in size, morphology, and colour with the description of trachoma virus given by Collier and Sowa (1958). Such bodies were numerous in some smears; in others they were scanty and it was then difficult to distinguish them from similar bodies sometimes seen in yolk-sac smears from uninoculated embryos of the same age.

Serological Investigations.-The serological relationship between the agent isolated (called T425) and the P-LGV group of viruses was tested by complement fixation. The method used was that of Meyer and Eddie (1956) for the detection of psittacosis antibodies, except that fixation was carried out for 17 hours at $4{ }^{\circ} \mathrm{C}$. The yolk sacs of three embryos dying on the 7th day after inoculation during the fourth passage of T425 were pooled and made into a 20 per cent. suspension in broth-saline which was centrifuged at $650 \mathrm{G}$. for 10 minutes. The fraction between the upper fatty layer and the deposit was used, both unheated and after heating for 20 minutes in a boiling water bath, as the "T425 preparations". The "Perth controls" were prepared from the yolk sacs of three uninoculated 15-day 
embryos in a similar manner. Those preparations, together with "ornithosislymphogranuloma venereum complement-fixing antigen", prepared by Commonwealth Serum Laboratories, Melbourne (CSL antigen), and its yolk-sac control (CSL control) were tested simultaneously against three human sera; psittacosis antibodies were reported, by other laboratories, to be present in two of those sera and absent from the third. The results given in Table II imply that the T425 preparations contained the heat-stable complement-fixing antigen of the P-LGV group of viruses.

TABLE II

RESULTS OF COMPLEMENT-FIXATION TEST

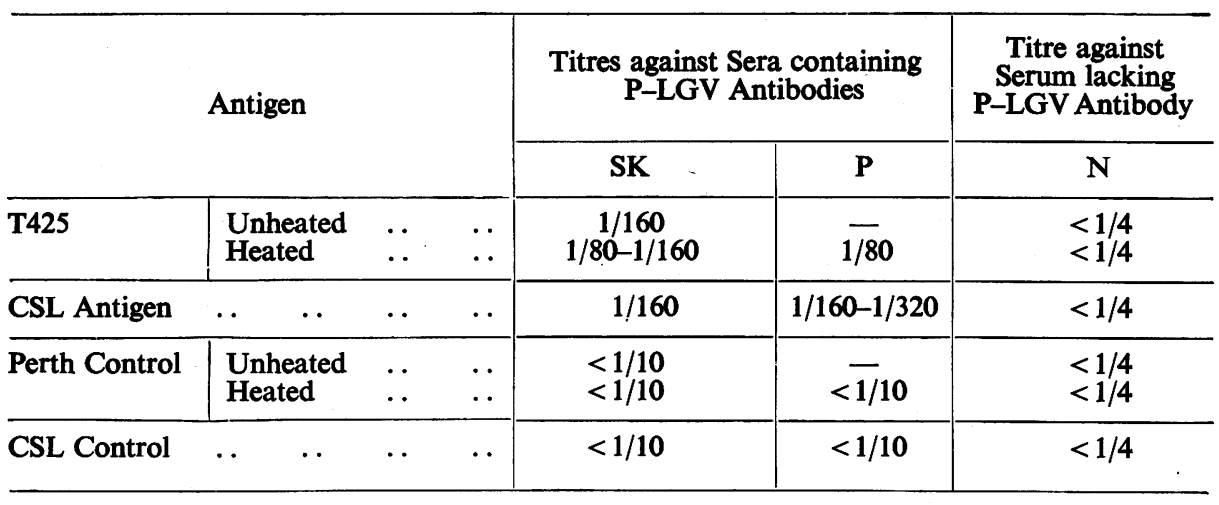

\section{Conclusions}

An agent of the psittacosis-lymphogranuloma venereum group of viruses has been isolated from embryonate eggs inoculated with conjunctival scrapings taken from a clinical case of trachoma in an Australian aboriginal child. The laboratory tests suggest that the agent has the characteristics of the trachoma virus isolated by T'ang and others (1957) and by Collier and Sowa (1958), but confirmation of its identity must await positive results from inoculation of the agent on to the conjunctiva of Rhesus monkeys and, if possible, of human volunteers.

We wish to thank Professor N. F. Stanley for his interest and advice; Mr. Ian Jack for providing sera; Miss J. Jenkyn for material used in complement-fixation tests; and Mrs. D. Martin for technical assistance.

\section{REFERENCES}

Collier, L. H., and Sowa, J. (1958). Lancet, 1, 993.

, DuKe-ElDER, S., and JONES, B. R. (1958). Brit. J. Ophthal., 42, 705.

Meyer, K. F., and EdDIE, B. (1956). In "Diagnostic Procedures for Virus and Rickettsial Diseases", 2nd ed., p. 409. American Public Health Association, New York City.

T"ANG, F. F., Chang, H. L., Huang, Y. T., and Wang, K. C. (1957). Chin. med. J., 75, 429. 